\title{
Migração internacional na Amazônia brasileira no Censo Demográfico de 2010
}

\section{International migration on the Brazilian Amazon in the Demographic Census 2010}

Jonatha Rodrigo de Oliveira Lira - Geógrafo; mestre em Geografia pela Universidade Federal do Pará; doutorando em Demografia pela Universidade Estadual de Campinas. E-mail: rodrrigao@hotmail.com

Daniel Esteban Quiroga - Historiador; mestre e doutor em Demografia pela Universidade Nacional de Córdoba. E-mail: danielestebanquiroga@gmail.com

\section{Resumo}

O objetivo principal deste artigo consiste em identificar novos padrões migratórios na Amazônia brasileira, tendo como objeto de pesquisa as mudanças na origem e nos fluxos da migração internacional na região. $\mathrm{O}$ estudo fundamenta-se no uso de dados censitários e na relevância da desagregação dos dados por sexo e país de origem, além da utilização do software Redatam+Sp para a decodificação dos microdados do Censo Demográfico brasileiro de 2010. A pesquisa permitiu demonstrar que os padrões dos fluxos migratórios internacionais, tradicionalmente originários da Europa e do Japão, sofreram mudanças significativas a partir da segunda metade do século XX, concentrando principalmente migrantes oriundos de países fronteiriços. Outra constatação apontada pelo estudo na análise da relação entre gêneros, baseada na divisão por sexo, revela que a distribuição espacial na Amazônia brasileira apresenta padrões diferenciados, conforme o país de origem dos imigrantes. Entre as razões que podem explicar esse fenômeno destacam-se a proximidade geográfica, as diferenças socioeconômicas entre os países amazônicos, o empoderamento da mulher e/ou a migração familiar.

\section{Palavras-chave}

Migração internacional. Amazônia brasileira. Países fronteiriços.

\begin{abstract}
This article aims to identify new migratory patterns in the Brazilian Amazon, primarily concerned with the changes in the source of international migration flow in the region. The study is based on the use of census data and on the relevance of data disaggregation by sex and country of origin, including the use of Redatam + Sp software to decode the micro data from the Brazilian National Census of 2010.Tne research permitted to show that the patterns of international migratory flows, traditionally coming from Europe and Japan, have undergone significant changes, starting during the second half of the 20th Century, concentrating mainly on migrants from neighboring countries. Another finding shown by the study in the analysis of relation between genders, based on the division by sex, reveals that the spatial distribution in the Brazilian Amazon presents different patterns, according to the immigrant's country of origin. Among the reasons that may explain this phenomenon are the geographical proximity, the socio economic differences among the Amazon countries, women's empowerment and/or the family migration
\end{abstract}

\section{Keywords}

International migration. Brasilian Amazon. Border countries. 


\section{INTRODUÇÃO}

A temática da migração internacional tem grande repercussão na mídia mundial e no meio acadêmico como uma das questões mais importantes a serem tratadas no século XXI. No entanto, na comunidade científica pouco se tem discutido sobre a migração internacional na Amazônia, limitada tanto pela falta de dados para estudos pontuais na região quanto pela sua dimensão continental e transnacional, dentre outros fatores (ARAGÓN, 2009).

Em decorrência dessas questões, os censos são considerados uma fonte de dados importante, porém ainda pouco explorada para estudos sobre migração internacional na Amazônia, seja a partir de estudos holísticos na Pan-Amazônia ou estudos específicos sobre os países amazônicos.

Neste sentido, este trabalho busca identificar as mudanças na origem da migração internacional na Amazônia brasileira, assim como a importância da migração feminina para este fluxo. No âmbito da pesquisa procedeu-se a análise das informações sobre migração acumulada, migração intercensitária e migração por data fixa, agregando dados sobre sexo e procedência, segundo os resultados obtidos no Censo Demográfico brasileiro de 2010.

\section{ASPECTOS HISTÓRICOS DA MIGRAÇÃO INTERNACIONAL NA AMAZÔNIA BRASILEIRA}

Para entender a dinâmica migratória internacional recente na Amazônia brasileira é necessário rever o contexto histórico das migrações internacionais direcionadas para a região. O processo migratório se inicia ainda no período colonial (século XVI), em que a chegada dos portugueses à Amazônia representava a apropriação das terras brasileiras pelos europeus, associada à migração forçada de escravos africanos que perdurou por três séculos (do século XVII ao XIX).

La migración internacional ha constituido un aspecto esencial de la historia de América Latina. En los cinco siglos que han transcurrido desde la ocupación de los territorios por los reinos de España y de Portugal, es posible identificar cuatro grandes etapas en el proceso migratorio. La primera se inicia con la Conquista y finaliza con la Independencia y se caracteriza por la incorporación de población que venía de los territorios metropolitanos y de población africana en régimen de esclavitud. La segunda, en la que los países de América Latina y el Caribe y muy particularmente la región sur del continente, recibieron una parte de la gran corriente de emigración europea de la segunda mitad del siglo XIX y principios del XX. La tercera fase transcurre desde 1930 hasta mediados de la década de 1960 y en ella el fenómeno dominante está dado por 
los movimientos internos de población hacia las grandes metrópolis; la migración internacional adquiere entonces un carácter regional y fronterizo y funciona como complemento de la migración interna. La cuarta fase se da en las últimas décadas del siglo XX, cuando el saldo migratorio pasa a ser sostenidamente negativo y la emigración hacia los Estados Unidos y otros países desarrollados se convierte en el hecho dominante del panorama migratorio de la región (PELLEGRINO, 2003, p. 11).

O processo de ocupação da Amazônia brasileira ocorreu nos moldes da ocupação do território brasileiro como um todo, com a entrada de imigrantes europeus e japoneses por diferentes razões políticas, econômicas e sociais, com os maiores volumes registrados no início do século XX. Agora, para a Amazônia brasileira, o momento é outro.

Os registros de uma nova dinâmica migratória nos últimos censos demográficos brasileiros mostra que houve grandes mudanças na origem e no volume de migrantes internacionais, que historicamente foi significativo para a formação da população na Amazônia brasileira, visto que o contingente que era bastante representativo.

Para Patarra e Baeninger (2006), as migrações internacionais contribuíram para a formação e composição da população brasileira desde a chegada dos portugueses no século XVI, passando pela inserção da mão de obra escrava, seguida pela mão de obra livre europeia vinculada à "necessidade" do sistema capitalista, e a partir de 1908, a migração de japoneses, particularmente para o estado de São Paulo. Essa "vocação" receptora brasileira declina a partir da década de 1950.

No caso dos movimentos migratórios dos países do Mercosul para o Brasil, pôde-se constatar a importância crescente dos movimentos intrablocos, não tanto pelo seu volume, mas pela sua diversidade e suas implicações. A reestruturação produtiva e o contexto internacional têm produzido efeitos nesta área, no sentido de impulsionar novas modalidades de transferências populacionais. Percebe-se que esse novo cenário tem influenciado a transferência populacional tanto para as metrópoles, como para outras cidades, cuja posição geográfica e competitividade têm atraído indústrias novas e internacionais, iniciado um processo de transformação urbana já típica da atual etapa de economia.

Em contrapartida, a questão das fronteiras e das áreas limítrofes entre os países apresenta uma outra faceta das mudanças nesses movimentos populacionais - são muitas as especificidades que cercam essa mobilidade. Em primeiro lugar, é possível que, em termos quantitativos, não esteja ocorrendo um aumento expressivo dos movimentos migratórios em consequência dos acordos comerciais, se por migração estivermos entendendo a transferência de residência fixa. Contudo, novas formas de mobilidade espacial da população passam a coexistir, incitando, inclusive, 
uma redefinição dos fenômenos emergentes que requerem análise (PATARRA; BAENINGER, 2006, p. 179).

Neste aspecto, Aragón (2009) ratifica:

O Brasil foi um dos destinos favoritos das grandes migrações de finais do século XIX e inícios do século XX, mantendo-se como um país receptor de migrantes até meados do século XX. Estima-se em mais de 5 milhões o número de imigrantes entre 1872 e 1972, vindos principalmente de Portugal, Itália, Japão, Alemanha e Espanha (LEVY, 1974). O censo brasileiro de 1900 registrou 1.074 .511 estrangeiros (6,16\% da população do país), aumentando, em 1920, para 1.565.961 (5,11\% da população total), quando o país registrou o maior número de estrangeiros de sua história conforme os censos. A partir deste ano a população estrangeira diminui constantemente até chegar a 651.226 pessoas no censo de $2000(0,38 \%$ da população), a mais baixa da história (PATARRA; BAENINGER, 2006). Entre 1950 e 1980 o Brasil foi considerado pelos especialistas como sendo de uma população fechada, ou seja, com crescimento populacional resultando quase que exclusivamente da relação entre nascimentos e mortes, dada a inexpressiva representação da migração internacional (baixíssima imigração e emigração). Mas a partir de 1980 o país passou a enviar uma quantidade cada vez maior de pessoas a outros países. Entre 1980 e 1990 estima-se uma perda líquida internacional de aproximadamente 1,8 milhão de pessoas com 10 anos ou mais de idade e entre 1991 e 2000 de 550 mil da mesma idade, convertendo-se o Brasil num país não mais receptor, mas expulsor de migrantes internacionais (CARVALHO; CAMPOS, 2006). De fato, conforme os registros consulares, em 2002 foram contabilizados 1.887.895 brasileiros residentes no exterior, principalmente nos Estados Unidos (42\%), no Paraguai (24\%) e no Japão (11\%) (PATARRA; BAENINGER, 2006; ARAGÓN, 2009, p. 12).

Villa e Pizarro (2001) afirmam que, mais importante que a dissecação dos volumes migratórios que hoje não são tão expressivos quanto anteriormente, a origem destes estrangeiros apresenta um fenômeno que requer uma atenção cuidadosa, não apenas para entender os novos fluxos que se apresentam nos dados demográficos, mas ampliar esse entendimento para outras dimensões também significativas, intimamente ligadas à migração deste novo contingente.

La migración internacional constituye uno de los factores de mayor importancia en la explicación de como evolucionaron las sociedades de América Latina y el Caribe. Más allá de la profundidad de sus raíces — de merecido reconocimiento en la historia - la persistencia y los sucesivos cambios de la migración no parecen haber encontrado una dedicación igualmente sostenida entre los decisores públicos de la región. El tema emerge a la luz cada cierto tiempo y como respuesta a la percepción de que alguno de sus efectos o características está configurando un problema de relevancia social. Así, con una frecuencia cada vez mayor, se alzan voces 
para expresar aspiraciones o visiones críticas sobre el tipo de inmigrantes que cabe estimular, aceptar o rechazar; ello suele conllevar el diseño o la reformulación de las normas que rigen los desplazamientos de personas a través de las fronteras (VILLA; PIZARRO, 2001, p. 22).

Jakob (2011) apresenta como explicação para as mudanças na origem dos estrangeiros que agora ocupam lugar de destaque nos números sobre migração internacional as melhorias em infraestrutura e comunicação, principalmente nas fronteiras internacionais. A expansão das fronteiras internacionais da Amazônia brasileira é outro fator que certamente possibilita e possibilitará desdobramentos significativos para essa região.

Dentre os componentes da dinâmica demográfica, os processos migratórios são os de mais difícil apreensão e aferição. A definição de um espaço e de um tempo específico é fundamental para caracterizar os tipos de fluxos migratórios, assim como para identificar as diferentes etapas do processo migratório. No caso das migrações internacionais, a questão ainda é bem mais complexa, pois envolve questões como a subenumeração de população, em decorrência da falta de declaração das pessoas que residem na situação de indocumentados, além de dizer respeito ao movimento entre países, o que dificulta a identificação dos emigrantes (JAKOB, 2011, p. 137).

Apesar das diferentes implicações na análise de dados sobre migração internacional na Amazônia brasileira, faz-se necessário entender os motivos dessa mudança de origem, assim como identificar os novos fluxos que surgem. Além do mais, há muitos questionamentos quanto à aferição, cobertura e conceitos por detrás dos dados sobre migração, o que necessitaria de uma pesquisa contínua e não estanque ${ }^{1}$.

Ressalta-se também a importância do software Redatam para o processamento das informações censitárias, devido à facilidade de utilização e a capacidade de processamento de um grande volume de informações.

\section{ASPECTOS RECENTES DA MIGRAÇÃO INTERNACIONAL NA AMAZÔNIA BRASILEIRA}

O Censo Demográfico brasileiro de 2010 contém uma série de dados que permite múltiplas análises sobre migração internacional, possibilitando diferentes recortes temporais e espaciais, além de estudos sobre imigração, emigração e

\footnotetext{
Desde a sua instituição por meio da Lei do Império, em 1872, o Censo Demográfico Brasileiro vem sendo realizado decenalmente, exceto nos períodos das Guerras Mundiais (1910 e 1930, respectivamente), quando não foi possível realizá-lo; e durante o governo Collor, realizou-se em 1991 (LIRA, 2010, p. 30).
} 
retorno. Neste trabalho, a análise dos dados fundamenta-se nas seguintes variáveis:

- País estrangeiro de nascimento;

- País de residência anterior;

- País de residência em 31/07/2005.

Essas informações foram utilizadas para analisar as possíveis mudanças na origem dos fluxos internacionais de imigração, emigração e retorno na Amazônia brasileira $^{2}$, assim como o cruzamento destas variáveis com a variável sexo do migrante para a correlação entre migração e gênero.

\subsection{A PRESENÇA ESTRANGEIRA NA AMAZÔNIA BRASILEIRA}

Neste tópico apresenta-se a análise dos dados oficiais sobre migração internacional na Amazônia brasileira, referente ao contingente de migrantes estrangeiros, segundo o gênero, país de nascimento e estrangeiros naturalizados residentes na região em 2010, com base no Censo Demográfico disponibilizado pelo Instituto Brasileiro de Geografia e Estatística (IBGE, 2010). Na tabela 1 encontram-se dados quantitativos.

Tabela 1 - País de nascimento dos imigrantes, 2010.

\begin{tabular}{|l|c|c|c|}
\hline Países & Homens & Mulheres & Total \\
\hline Bolívia & 2611 & 2703 & 5314 \\
\hline Peru & 3234 & 1869 & 5102 \\
\hline Paraguai & 1316 & 1557 & 2873 \\
\hline Portugal & 1620 & 849 & 2469 \\
\hline Japão & 1305 & 1107 & 2412 \\
\hline Colômbia & 1180 & 1039 & 2219 \\
\hline Guiana & 841 & 953 & 1795 \\
\hline Estados Unidos & 786 & 659 & 1444 \\
\hline Espanha & 671 & 336 & 1006 \\
\hline Itália & 546 & 386 & 932 \\
\hline França & 517 & 172 & 689 \\
\hline Guiana Francesa & 395 & 270 & 665 \\
\hline Venezuela & 361 & 280 & 640 \\
\hline
\end{tabular}

2 Neste trabalho considera-se a delimitação da Amazônia brasileira proposta por Carmo e Jakob (2009), que engloba todos os estados da Região Norte do Brasil (Acre, Amazonas, Amapá, Pará, Rondônia, Roraima e Tocantins) e os estados de Mato Grosso (Centro-Oese) e Maranhão (Nordeste). Na delimitação oficial nomeada de Amazônia Legal, o território do estado do Maranhão limita-se ao meridiano 44, porém esta definição envolve questões muito complexas em termos sociais e ambientais, com frequentes pressões político-administrativas para a incorporação da área total dos municípios a leste do meridiano 44, visto que facilita a comparação com a divisão política das Unidades de Federação e não altera as análises. 


\begin{tabular}{|c|c|c|c|}
\hline Alemanha & 357 & 248 & 605 \\
\hline Argentina & 347 & 175 & 522 \\
\hline Cuba & 299 & 131 & 429 \\
\hline China & 208 & 176 & 384 \\
\hline Chile & 279 & 84 & 363 \\
\hline Líbano & 153 & 81 & 234 \\
\hline Suriname & 117 & 105 & 222 \\
\hline México & 119 & 95 & 215 \\
\hline Uruguai & 141 & 69 & 210 \\
\hline Índia & 129 & 44 & 173 \\
\hline República Da Coreia & 63 & 105 & 168 \\
\hline Holanda & 82 & 60 & 142 \\
\hline Angola & 79 & 58 & 138 \\
\hline Canadá & 79 & 46 & 125 \\
\hline Escócia & 78 & 42 & 120 \\
\hline Cabo Verde & 22 & 93 & 115 \\
\hline Guiné Bissau & 106 & 6 & 112 \\
\hline Costa do Marfim & 64 & 45 & 109 \\
\hline Suíça & 52 & 32 & 84 \\
\hline Síria & 54 & 25 & 80 \\
\hline Rússia & 32 & 45 & 76 \\
\hline Não soube informar o país & 47 & 23 & 70 \\
\hline Paquistão & 41 & 26 & 67 \\
\hline Polônia & 19 & 37 & 55 \\
\hline Iraque & 26 & 26 & 51 \\
\hline Panamá & 34 & 8 & 43 \\
\hline Noruega & 3 & 35 & 39 \\
\hline Arábia Saudita & 36 & - & 36 \\
\hline Moçambique & - & 36 & 36 \\
\hline Nicarágua & - & 35 & 35 \\
\hline Turquia & 32 & - & 32 \\
\hline Israel & 32 & - & 32 \\
\hline Malásia & 11 & 21 & 32 \\
\hline Equador & 8 & 23 & 31 \\
\hline Finlândia & 2 & 25 & 28 \\
\hline Bélgica & 21 & 6 & 27 \\
\hline África do Sul & 4 & 22 & 26 \\
\hline Ucrânia & 26 & - & 26 \\
\hline Jordânia & 18 & 7 & 25 \\
\hline Indonésia & 24 & - & 24 \\
\hline Grécia & 23 & - & 23 \\
\hline São Tomé e Príncipe & - & 23 & 23 \\
\hline Costa Rica & 5 & 18 & 22 \\
\hline Trinidad e Tobago & - & 22 & 22 \\
\hline Irã & 20 & - & 20 \\
\hline Guiné & 20 & - & 20 \\
\hline
\end{tabular}




\begin{tabular}{|l|c|c|c|}
\hline Hungria & 19 & - & 19 \\
\hline Bulgária & 18 & - & 18 \\
\hline Camarões & 17 & - & 17 \\
\hline Camboja & 14 & - & 14 \\
\hline El Salvador & 9 & 4 & 13 \\
\hline Niger & 13 & - & 13 \\
\hline Tailândia & 13 & - & 13 \\
\hline República Dominicana & - & 12 & 12 \\
\hline República Tcheca & - & 12 & 12 \\
\hline Oman & 10 & - & 10 \\
\hline Santa Lúcia & 9 & - & 9 \\
\hline Togo & 6 & - & 6 \\
\hline Sudão & 6 & - & 6 \\
\hline República Democrática Popular de Laos & 5 & - & 5 \\
\hline Guatemala & 5 & - & 5 \\
\hline Egito & 5 & - & 5 \\
\hline Quênia & 3 & - & 3 \\
\hline Ignorado & - & 3 & 3 \\
\hline Tanzânia & - & 2 & 2 \\
\hline Irlanda & 2 & - & 2 \\
\hline Total & 18.849 & 14.370 & 33.219 \\
\hline
\end{tabular}

Fonte: Censo Demográfico (IBGE, 2010).

Os dados demonstram que em 2010 havia 33.219 estrangeiros na região, sendo 18.849 homens e 14.370 mulheres. Quanto à procedência dos migrantes, segundo o país de origem, verifica-se que os contingentes mais expressivos são oriundos da Bolívia, Peru e Paraguai. Ressalta-se que esses países fazem fronteira com o Brasil.

Considerando que os dados da Tabela 1 estão associados à migração acumulada, também merecem destaque Portugal e Japão, com o quarto e o quinto maior volume de migrantes na região. Todavia, essas informações referem-se essencialmente à chegada de migrantes, sem haver recorte temporal, neste caso, o Censo de 2010 demonstra que os maiores volumes provêm da migração europeia e japonesa.

Contudo, em termos do volume total de migrantes, o Censo Demográfico evidencia a importância dos países fronteiriços. Destaca-se ainda a maior quantidade de mulheres, em comparação ao contingente de homens, originários da Bolívia e do Paraguai.

Nos últimos 10 anos, período intercensitário, observa-se que diminui a participação de igrantes de países europeus nos fluxos, comprovando a importância do caráter fronteiriço das migrações internacionais na Amazônia brasileira (Tabela 2). 
Tabela 2 - País de residência anterior, 2010.

\begin{tabular}{|c|c|c|c|}
\hline Países & Homens & Mulheres & Total \\
\hline Peru & 1454 & 843 & 2297 \\
\hline Bolívia & 848 & 856 & 1704 \\
\hline Colômbia & 621 & 519 & 1140 \\
\hline Estados Unidos & 512 & 462 & 974 \\
\hline Portugal & 429 & 217 & 647 \\
\hline Paraguai & 267 & 316 & 582 \\
\hline Espanha & 386 & 186 & 572 \\
\hline Guiana & 241 & 228 & 468 \\
\hline Japão & 181 & 271 & 452 \\
\hline Guiana Francesa & 253 & 144 & 396 \\
\hline Venezuela & 186 & 134 & 321 \\
\hline França & 205 & 97 & 302 \\
\hline Itália & 200 & 54 & 254 \\
\hline Cuba & 157 & 64 & 221 \\
\hline Alemanha & 110 & 80 & 190 \\
\hline Suriname & 116 & 72 & 188 \\
\hline Argentina & 129 & 47 & 177 \\
\hline México & 76 & 86 & 162 \\
\hline Cabo Verde & 21 & 105 & 126 \\
\hline República da Coreia & 42 & 83 & 125 \\
\hline Ignorado & 50 & 57 & 108 \\
\hline Canadá & 42 & 39 & 81 \\
\hline Guiné Bissau & 79 & - & 79 \\
\hline Escócia & 27 & 49 & 76 \\
\hline China & 43 & 24 & 67 \\
\hline Suíça & 42 & 25 & 67 \\
\hline Holanda & 34 & 14 & 49 \\
\hline Líbano & 40 & - & 40 \\
\hline Uruguai & 14 & 26 & 40 \\
\hline Noruega & - & 35 & 35 \\
\hline Panamá & 34 & - & 34 \\
\hline Índia & 17 & 17 & 34 \\
\hline Angola & - & 32 & 32 \\
\hline Santa Lúcia & 13 & 19 & 32 \\
\hline Filipinas & 17 & 9 & 26 \\
\hline Finlândia & 23 & - & 23 \\
\hline São Tomé e Príncipe & - & 23 & 23 \\
\hline Ucrânia & - & 21 & 21 \\
\hline República da Moldávia & - & 21 & 21 \\
\hline Equador & 8 & 13 & 21 \\
\hline Polônia & - & 18 & 18 \\
\hline Não soube informar o país & - & 15 & 15 \\
\hline Chile & 15 & - & 15 \\
\hline Costa do Marfim & - & 13 & 13 \\
\hline
\end{tabular}




\begin{tabular}{|l|c|c|c|}
\hline Dominica & 12 & - & 12 \\
\hline Paquistão & - & 12 & 12 \\
\hline Islândia & - & 11 & 11 \\
\hline Camarões & 10 & - & 10 \\
\hline Papua Nova Guiné & 5 & 5 & 10 \\
\hline Hungria & 9 & - & 9 \\
\hline San Marino & - & 6 & 6 \\
\hline Bélgica & 5 & - & 5 \\
\hline Guatemala & 5 & - & 5 \\
\hline África do Sul & 4 & - & 4 \\
\hline El Salvador & - & 4 & 4 \\
\hline Quênia & 3 & - & 3 \\
\hline Tanzânia & - & 2 & 2 \\
\hline Irlanda & 2 & - & 2 \\
\hline Total & 6.986 & 5.374 & 12.360 \\
\hline
\end{tabular}

Fonte: Censo Demográfico (IBGE, 2010).

A Tabela 2 mostra que dos 33.219 estrangeiros e naturalizados residentes na Amazônia brasileira, 12.360 vieram de outro país durante o período intercensitário, de 2000-2010. Destaca-se a procedência dos países fronteiriços Peru, Bolívia e Colômbia, assim como de imigrantes vindos dos Estados Unidos. Na análise por sexo, Bolívia e Paraguai merecem destaque em termos quantitativos, mesmo com o volume reduzido, mostrando ainda a maior participação feminina em relação à masculina.

A Tabela 3 apresenta informações sobre estrangeiros e naturalizados que chegaram em 31 de Julho de 2010 na Amazônia brasileira com um volume total de 7.101 pessoas destacando-se ainda os países fronteiriços Peru, Bolívia e Colômbia e também a vinda proveniente dos Estados Unidos. Segundo os dados, a participação europeia também diminuiu, mas, por outro lado, aumentou a participação japonesa neste período. A participação feminina tem destaque nos fluxos provenientes do Japão, Guiana e Paraguai.

Tabela 3 - País de residência em 31/07/2005.

\begin{tabular}{|l|c|c|c|}
\hline Países & Homens & Mulheres & Total \\
\hline Peru & 754 & 448 & 1202 \\
\hline Bolívia & 580 & 493 & 1072 \\
\hline Colômbia & 401 & 296 & 698 \\
\hline Estados Unidos & 340 & 219 & 559 \\
\hline Japão & 143 & 213 & 356 \\
\hline Portugal & 250 & 98 & 348 \\
\hline Guiana & 128 & 144 & 271 \\
\hline Paraguai & 110 & 143 & 253 \\
\hline
\end{tabular}




\begin{tabular}{|c|c|c|c|}
\hline França & 128 & 83 & 211 \\
\hline Guiana Francesa & 128 & 52 & 180 \\
\hline Venezuela & 96 & 74 & 170 \\
\hline Espanha & 149 & 5 & 154 \\
\hline Alemanha & 89 & 63 & 152 \\
\hline Itália & 97 & 48 & 145 \\
\hline Argentina & 72 & 60 & 132 \\
\hline Cabo Verde & 21 & 105 & 126 \\
\hline México & 53 & 72 & 125 \\
\hline Cuba & 72 & 52 & 124 \\
\hline Guiné Bissau & 99 & - & 99 \\
\hline Canadá & 64 & 25 & 89 \\
\hline Costa do Marfim & 32 & 45 & 77 \\
\hline Holanda & 38 & 14 & 53 \\
\hline China & 24 & 24 & 48 \\
\hline Suíça & 42 & 3 & 45 \\
\hline Ignorado & 21 & 16 & 36 \\
\hline Suriname & 36 & - & 36 \\
\hline Noruega & - & 35 & 35 \\
\hline Líbano & 34 & - & 34 \\
\hline Angola & - & 29 & 29 \\
\hline Panamá & 29 & - & 29 \\
\hline Filipinas & 17 & 9 & 26 \\
\hline Uruguai & 15 & 10 & 25 \\
\hline São Tomé e Príncipe & - & 23 & 23 \\
\hline Ucrânia & - & 21 & 21 \\
\hline Não soube informar o país & 20 & - & 20 \\
\hline Índia & - & 17 & 17 \\
\hline Escócia & 6 & 11 & 17 \\
\hline Chile & 14 & - & 14 \\
\hline Equador & 12 & - & 12 \\
\hline Dominica & 12 & - & 12 \\
\hline Togo & 6 & - & 6 \\
\hline Sudão & 6 & - & 6 \\
\hline Guatemala & 5 & - & 5 \\
\hline Costa Rica & - & 5 & 5 \\
\hline El Salvador & - & 4 & 4 \\
\hline Total & 4.142 & 2.959 & 7.101 \\
\hline
\end{tabular}

Fonte: Censo Demográfico (IBGE, 2010).

No caso da migração internacional de estrangeiros e naturalizados brasileiros, conclui-se que os países fronteiriços constituem as novas origens da migração internacional para Amazônia brasileira, e provavelmente deve ocorrer um aumento da circulação desses imigrantes na região, em detrimento de outras nacionalidades e regiões. 


\subsection{O REGRESSO DE MIGRANTES BRASILEIROS PARA A AMAZÔNIA}

O regresso de brasileiros do exterior para a Amazônia brasileira é considerado a partir do município de origem dos imigrantes. Utilizam-se os critérios censitários referentes ao local de nascimento dos indivíduos e a moradia por um determinado período em algum país no exterior. Dessa forma, foi possível obter informações sobre a origem e o retorno do exterior daqueles indivíduos que nasceram no município em que residem atualmente, com base no Censo Demográfico de 2010.

A Tabela 4 mostra os dados sobre os imigrantes brasileiros que retornaram do exterior para a Amazônia no período de 2000-2010, segundo o sexo e o país de procedência. Para este período, 9.957 brasileiros retornaram para o seu município de origem na região, sendo 5.634 homens e 4.314 mulheres, com destaque para a procedência do Paraguai, Estados Unidos e Japão.

Apesar da importância dos fluxos provenientes dos Estados Unidos e Japão, mas no total de migrantes nota-se a procedência de cinco países fronteiriços nas 10 primeiras posições, destacando-se também a participação feminina procedente de Portugal e Suriname.

Tabela 4 - País de residência anterior, 2010.

\begin{tabular}{lccc}
\hline Países & Homens & Mulheres & Total \\
\hline Paraguai & 1112 & 814 & 1926 \\
Estados Unidos & 1213 & 663 & 1877 \\
Japão & 609 & 505 & 1114 \\
Espanha & 405 & 484 & 889 \\
Portugal & 420 & 433 & 853 \\
Guiana Francesa & 285 & 253 & 539 \\
Bolívia & 268 & 140 & 408 \\
Venezuela & 184 & 115 & 299 \\
Ignorado & 148 & 135 & 283 \\
Suriname & 99 & 112 & 211 \\
Guiana & 123 & 83 & 206 \\
Escócia & 75 & 119 & 193 \\
Itália & 68 & 68 & 136 \\
França & 82 & 47 & 129 \\
Peru & 41 & 43 & 84 \\
Chile & 46 & 35 & 81 \\
Cuba & 30 & 51 & 81 \\
Argentina & 63 & 15 & 77 \\
Suíça & 36 & 34 & 71 \\
Alemanha & 33 & 14 & 47 \\
Angola & 45 & - & 45
\end{tabular}




\begin{tabular}{lccc} 
Irlanda & 2 & 31 & 33 \\
Moçambique & 17 & 17 & 33 \\
Canadá & 16 & 17 & 33 \\
Finlândia & 5 & 25 & 30 \\
Colômbia & 23 & 4 & 27 \\
São Tomé e Príncipe & 22 & 5 & 27 \\
Áustria & 17 & 9 & 26 \\
Santa Lúcia & 17 & 6 & 24 \\
África do Sul & 19 & - & 19 \\
Não soube informar o país & 9 & 9 & 18 \\
Bélgica & 14 & 2 & 16 \\
Macedônia & 14 & - & 14 \\
Niger & 13 & - & 13 \\
China & 13 & - & 13 \\
Suécia & 11 & - & 11 \\
Mianmar & 11 & - & 11 \\
Equador & 6 & 6 & 11 \\
Malásia & - & 11 & 11 \\
Nigéria & 10 & - & 10 \\
Panamá & - & 10 & 10 \\
Congo & 6 & - & 6 \\
Gabão & 5 & - & 5 \\
Guatemala & 5 & - & 5 \\
Haiti & 4 & - & 4 \\
Timor Leste & - & 2 & 2 \\
\hline Total & 5.643 & 4.314 & 9.957 \\
\hline
\end{tabular}

Fonte: Censo Demográfico (IBGE, 2010).

A partir do recorte temporal da Tabela 5, em termos absolutos observa-se que não houve grande redução na quantidade de imigrantes que retornaram ao Brasil no período intercensitário (2000-2010), precisamente data fixa de 31 de julho de 2005. Constata-se que dos 9.957 brasileiros que regressaram ao país nos últimos 10 anos, 8.118 encontravam-se em outros países em 2005, destacando-se os maiores contingentes nos Estados Unidos, Japão e Portugal, como também a Espanha apresentou maior participação feminina no período.

Tabela 5 - País de residência em 31/07/2005.

\begin{tabular}{lccc}
\hline Países & Homens & Mulheres & Total \\
\hline Estados Unidos & 1447 & 734 & 2180 \\
Japão & 611 & 475 & 1086 \\
Portugal & 423 & 369 & 792 \\
Espanha & 232 & 310 & 543 \\
Guiana Francesa & 258 & 249 & 508
\end{tabular}




\begin{tabular}{|c|c|c|c|}
\hline Paraguai & 324 & 180 & 504 \\
\hline Bolívia & 180 & 182 & 362 \\
\hline Suriname & 171 & 84 & 255 \\
\hline França & 122 & 106 & 228 \\
\hline Escócia & 116 & 111 & 228 \\
\hline Venezuela & 129 & 73 & 202 \\
\hline Guiana & 121 & 46 & 168 \\
\hline Ignorado & 67 & 81 & 148 \\
\hline Bélgica & 99 & 39 & 137 \\
\hline Itália & 66 & 55 & 120 \\
\hline Cuba & 40 & 40 & 80 \\
\hline Canadá & 37 & 37 & 74 \\
\hline Suíça & 38 & 36 & 74 \\
\hline Alemanha & 44 & 13 & 57 \\
\hline Argentina & 30 & 16 & 46 \\
\hline Moçambique & 28 & 17 & 45 \\
\hline Angola & 36 & - & 36 \\
\hline Não soube informar o país & 18 & 9 & 27 \\
\hline Finlândia & - & 25 & 25 \\
\hline Peru & 18 & 6 & 24 \\
\hline Irlanda & 13 & 6 & 18 \\
\hline Panamá & 5 & 10 & 15 \\
\hline Colômbia & 12 & - & 12 \\
\hline Geórgia & 12 & - & 12 \\
\hline Timor Leste & - & 12 & 12 \\
\hline Nova Zelândia & 10 & - & 10 \\
\hline República Centro Africana & - & 10 & 10 \\
\hline China & - & 10 & 10 \\
\hline México & - & 9 & 9 \\
\hline Chile & - & 9 & 9 \\
\hline Gabão & 9 & - & 9 \\
\hline Haiti & 9 & - & 9 \\
\hline Turquia & 7 & - & 7 \\
\hline Congo & 6 & - & 6 \\
\hline Costa Rica & 5 & - & 5 \\
\hline Cabo Verde & 4 & - & 4 \\
\hline Santa Lúcia & 4 & - & 4 \\
\hline Suécia & 3 & - & 3 \\
\hline Equador & 3 & - & 3 \\
\hline Total & 4.760 & 3.358 & 8.118 \\
\hline
\end{tabular}

Fonte: Censo Demográfico (IBGE, 2010).

No caso dos imigrantes brasileiros que retornaram a região amazônica, a migração fronteiriça não obteve grande destaque quanto à migração proveniente dos Estados Unidos, da Europa e da Ásia (sobretudo Japão). Todavia, no 
conjunto dos principais fluxos, vários países fronteiriços ocupavam as 10 primeiras posições, indicando a necessidade de se compreender o porquê desse retorno e do quantitativo menor que o dos países Europeus, do Japão e dos Estados Unidos, principalmente nos últimos cinco anos. A reduzida participação feminina no retorno à região amazônica, segundo os países de procedência, é uma questão relevante, que necessita maior aprofundamento.

\subsection{Emigração internacional de brasileiros}

A emigração internacional foi a grande novidade no Censo Demográfico brasileiro de 2010 para estudos sobre migração, sendo uma informação nunca contabilizada nas pesquisas anteriores do Censo Demográfico brasileiro.

Cabe ressaltar que esses primeiros dados censitários sobre emigração são parciais e, portanto, não podem ser considerados como o total de emigrantes, visto que essas informações são coletadas indiretamente, com o levantamento de dados junto a outros membros do domicílio pesquisado, que informam sobre os familiares residentes no exterior.

A Tabela 6 mostra os países de residência de brasileiros procedentes da Amazônia brasileira em 31 de julho de 2005. Do total de 59.527 emigrantes residentes fora do país, 25.817 eram homens e 33.710 mulheres, com destaque para a Espanha, Estados Unidos, Portugal e Bolívia, entretanto, apenas na Bolívia a participação feminina foi inferior à masculina.

Tabela 6 - País de residência em 31/07/2005.

\begin{tabular}{|l|c|c|c|}
\hline Países & Homens & Mulheres & Total \\
\hline Espanha & 2949 & 6522 & 9471 \\
\hline Estados Unidos & 3634 & 3994 & 7628 \\
\hline Portugal & 2421 & 4174 & 6595 \\
\hline Bolívia & 2727 & 1888 & 4615 \\
\hline França & 1585 & 2458 & 4043 \\
\hline Guiana Francesa & 2264 & 1579 & 3842 \\
\hline Suriname & 2021 & 1536 & 3557 \\
\hline Japão & 1614 & 1450 & 3064 \\
\hline Itália & 549 & 1652 & 2201 \\
\hline Suíça & 359 & 1556 & 1915 \\
\hline Venezuela & 854 & 877 & 1731 \\
\hline Escócia & 712 & 852 & 1564 \\
\hline Alemanha & 311 & 836 & 1147 \\
\hline Guiana & 705 & 414 & 1119 \\
\hline Holanda & 362 & 745 & 1107 \\
\hline
\end{tabular}




\begin{tabular}{|c|c|c|c|}
\hline Argentina & 348 & 381 & 729 \\
\hline Colômbia & 230 & 218 & 448 \\
\hline Bélgica & 134 & 296 & 430 \\
\hline Canadá & 112 & 269 & 381 \\
\hline Irlanda & 218 & 140 & 357 \\
\hline Austrália & 77 & 209 & 287 \\
\hline Paraguai & 111 & 155 & 266 \\
\hline Peru & 106 & 132 & 238 \\
\hline Angola & 177 & 40 & 217 \\
\hline Dinamarca & 26 & 173 & 199 \\
\hline África do Sul & 177 & 18 & 195 \\
\hline Cuba & 97 & 78 & 174 \\
\hline Chile & 45 & 120 & 165 \\
\hline Noruega & 22 & 133 & 155 \\
\hline México & 29 & 102 & 130 \\
\hline Israel & 84 & 17 & 101 \\
\hline Suécia & 43 & 46 & 88 \\
\hline Luxemburgo & 22 & 57 & 78 \\
\hline Áustria & 33 & 43 & 76 \\
\hline Timor Leste & 18 & 56 & 74 \\
\hline Não soube informar o país & 67 & 5 & 72 \\
\hline Iraque & 26 & 45 & 71 \\
\hline Equador & 43 & 15 & 58 \\
\hline Uruguai & 23 & 34 & 57 \\
\hline Haiti & 44 & 5 & 48 \\
\hline Grécia & 25 & 21 & 46 \\
\hline Turquia & 21 & 21 & 42 \\
\hline Emirados Árabes & 8 & 32 & 40 \\
\hline Nova Zelândia & 26 & 14 & 40 \\
\hline Nicarágua & 19 & 19 & 37 \\
\hline República Democrática do Congo & 35 & - & 35 \\
\hline Islândia & 23 & 12 & 35 \\
\hline Finlândia & 8 & 27 & 34 \\
\hline Romênia & 34 & - & 34 \\
\hline Ignorado & 20 & 9 & 28 \\
\hline Moçambique & 6 & 21 & 27 \\
\hline Marrocos & 22 & - & 22 \\
\hline Guiné Equatorial & 22 & - & 22 \\
\hline Rússia & 21 & - & 21 \\
\hline Costa Rica & 21 & - & 21 \\
\hline Síria & 9 & 11 & 21 \\
\hline Bulgária & 16 & - & 16 \\
\hline
\end{tabular}




\begin{tabular}{|l|c|c|c|}
\hline Índia & 10 & 5 & 15 \\
\hline Belize & - & 15 & 15 \\
\hline Brunei Darussalan & - & 14 & 14 \\
\hline Arábia Saudita & - & 14 & 14 \\
\hline China & - & 13 & 13 \\
\hline Malawi & - & 13 & 13 \\
\hline Congo & 12 & - & 12 \\
\hline Líbia & 12 & - & 12 \\
\hline Tunísia & 12 & - & 12 \\
\hline Tailândia & - & 12 & 12 \\
\hline Bósnia E Herzegovina & - & 11 & 11 \\
\hline Senegal & - & 11 & 11 \\
\hline Quênia & - & 11 & 11 \\
\hline Guatemala & - & 11 & 11 \\
\hline Ucrânia & - & 11 & 11 \\
\hline Chipre & - & 11 & 11 \\
\hline Vietnã & - & 10 & 10 \\
\hline Panamá & 10 & - & 10 \\
\hline Montenegro & 10 & - & 10 \\
\hline Geórgia & 10 & - & 10 \\
\hline Indonésia & - & 9 & 9 \\
\hline San Marino & 9 & - & 9 \\
\hline Camboja & - & 9 & 9 \\
\hline República Tcheca & - & 9 & 9 \\
\hline Iêmen & - & 9 & 9 \\
\hline Trinidad e Tobago & - & - & 7 \\
\hline Burundi & - & - & 6 \\
\hline Honduras & - & - & 5 \\
\hline Nigéria & - & 33.710 & 59.527 \\
\hline Guiné Bissau & & 3 \\
\hline Sérvia & - & - & 3 \\
\hline Total & - & - & 2 \\
\hline
\end{tabular}

Fonte: Censo Demográfico (IBGE, 2010).

Diante da apresentação dos dados sobre emigração internacional em que a participação feminina é notadamente muito superior a masculina, vale destacar algumas informações importantes nas análises dos diferentes fluxos internacionais com base nos dados sobre a categoria de gênero, a partir da divisão por sexo. 


\section{MIGRAÇÃO INTERNACIONAL NA AMAZÔNIA BRASILEIRA: UMA QUESTÃO DE GÊNERO}

A partir das análises sobre migração internacional na Amazônia brasileira no que se refere à correlação dos contingentes por sexo, deve-se ressaltar a importância das relações de gênero, assim como a necessidade de se incorporar um aporte teórico específico para a análise deste fenômeno. As informações sobre a categoria sexo, para além dos volumes migratórios “assexuados", presentam diferenças significativas,por exemplo, quanto à origem dos fluxos migratórios.

Todavia, somente a descrição da diferença de gênero entre homens e mulheres não é suficiente para explicar as especificidades desses fluxos, porém, possibilita um reencaminhamento das pesquisas, incorporando uma informação pouco utilizada nos estudos sobre as mudanças atuais da migração internacional.

Avanços teóricos recentes dos estudos de migração ressaltam a importância de se estudar diferenciais por sexo, transformações nas relações de gênero e também de um aporte específico para este fenômeno. Ao incorporar os diferenciais por sexo, bem como as relações de gênero às análises de fluxos migratórios, indo além da descrição das diferenças entre homens e mulheres, as teorias de migração avançam no sentindo de compreender as experiências das mulheres migrantes em esferas específicas - família, domicílio, mercado de trabalho. Segundo Pessar (2000), há importantes intersecções entre transformações dos papéis de gênero, estratégias migratórias e inserção em diferentes mercados de trabalho ao longo do projeto migratório. A interdependência dessas estruturas causa diferentes impactos principalmente entre as mulheres, que são mais suscetíveis a essas transformações (PERES, 2013, p. 116).

Um primeiro caminho seria entender as diferentes trajetórias migratórias, pois tanto na imigração quanto na emigração como também no retorno, esses homens e mulheres têm destinos diversificados. Contudo, de acordo com Peres (2013), as “trajetórias migratórias não se definem, portanto, apenas no percurso percorrido pelos migrantes em direção a seu destino: é importante apreender o uso estratégico de cada um dos espaços componentes desta trajetória, em suas variadas formas" (Peres, 2013, p. 122).

\section{CONSIDERAÇÕES FINAIS}

O Censo Demográfico Brasileiro de 2010 tem sido uma fonte de dados subexplorada, no que se refere à migração internacional. Quando focalizamos a análise na dinâmica migratória internacional que ocorre na Amazônia brasileira, 
esta informação é ainda mais contundente, visto que há poucos trabalhos que abordam essa modalidade migratória na região.

Portanto, este artigo busca evidenciar a importância desta fonte de dados para estudos sobre migração internacional, em virtude da relevância desse problema em escala mundial. $\mathrm{O}$ recorte estabelecido para a análise teve o propósito demonstrar o interesse que a região amazônica tem despertado para atrair os fluxos migratórios de estrangeiros.

Segundo Aragón (2009), apesar das suas limitações, os censos são fontes de essenciais para estudos sobre migração internacional e seus impactos. Nas diretrizes desta pesquisa, os dados do Censo Demográfico de 2010 são as fontes principais e as contribuições do trabalho podem suscitar novos estudos sobre os padrões e os fluxos migratórios na Amazônia brasileira, associados à imigração, emigração e retorno em diferentes contextos históricos, e outras questões emergentes que carecem de aprofundamento.

Cabe a nós, pesquisadores, analisar como se processam esses movimentos, quem são esses indivíduos, qual é o impacto para o desenvolvimento do país e da região amazônica, a melhoria da qualidade de vida desses migrantes e de suas famílias, buscando entender o porquê de uns voltarem e outros ficarem. Presume-se que as comparações entre censos anteriores e de outros países, sobretudo países fronteiriços como Bolívia e Paraguai, permitirão identificar tendências sobre este fenômeno.

\section{REFERÊNCIAS}

ARAGÓN, L. E. Aproximação ao estudo da migração internacional na PanAmazônia. In: ARAGÓN, L. E. (Org.). Migração Internacional na PanAmazônia. Belém: NAEA/UFPA, 2009. p. 11-38.

JAKOB, A. A. E. A migração internacional na Amazônia brasileira. In: Encontro Nacional sobre Migrações: migrações, políticas públicas e desigualdades regionais, 7. 2011. Curitiba. Anais... Curitiba, 2011, /PR.

JAKOB, A.A.E. A migração internacional na Amazônia brasileira. Informe GEPEC - Revista de Desenvolvimento Regional e Agronegócio, v. 15, p. 367-385, 2011.

PATARRA, N. L.; BAENINGER, R. Mobilidade espacial da população no Mercosul, metrópoles e fronteira. Revista Brasileira de Ciências Sociais, v. 21 , n. 60 , p. $83-181,2006$ 
PELLEGRINO, A. La migración internacional en América Latina y el Caribe: tendencias y perfiles de los migrantes. Población y Desarrollo, v. 41, n. 35, 2003. PERES, R.G. Mulheres na fronteira: imigração e gênero. In: BAENINGER, R. (Org.). Migração Internacional. Campinas: Nepo/Unicamp, 2013. p.115-163 (Por dentro do estado de São Paulo, v. 9).

LIRA, J. R.O. Espacialização da migração internacional na Amazônia brasileira. Trabalho de Conclusão de Curso (Licenciatura e Bacharelado em Geografia) - Instituto de Filosofia e Ciências Humanas, UFPA, Belém, 2010.

VILLA, M.; PIZARRO, J. M. Tendencias y patrones de la migración internacional en América Latina y el Caribe. In: La migración internacional y el desarrollo en las Américas. Santiago: CEPAL, 2001. p.21-60. 